THE WABASH CENTER

JOURNAL oN TEACHING

\title{
Making Learning-Centered Teaching Work: Practical Strategies for Implementation (2nd Edition)
}

\author{
Phyllis Blumberg \\ Sterling, VA: Stylus Publishing, 2019 (vii + 280 pages, ISBN 978-1-62036-895-4, \\ \$37.50)
}

\author{
Reviewed By \\ Mary Ann Zimmer \\ Marywood University
}

Phyllis Blumberg is an independent consultant who spent ten years as the director of the Teaching and Learning Center at the University of the Sciences in Philadelphia among other faculty development roles. She draws from all that experience in this workbook of learningcentered teaching, an extremely rich serving of both wisdom and strategy. Blumberg makes the complex practice of learning-centered teaching clear through careful analysis of its parts, numerous examples, and abundant guidance for assessment.

She has her audience in mind and includes numerous examples from a range of disciplines, numerous opportunities for detailed self-reflection, and recommendations for a variety of ways a time-pressed instructor might choose to use this material. While providing plentiful detail, Blumberg herself recommends that faculty might begin by identifying the areas that are most important to them-whether individual, study group, or program. She even provides a chart in the preface for a range of disciplines and teaching concerns that are likely to be of particular interest so that instructors can easily locate the discussion that addresses their immediate concerns. In this way she provides relief for those instructors who might be reluctant to wrestle with such a dense volume.

Blumberg divides the book into two sections with three appendices. In the first section she describes learning-centered teaching and unpacks the five elements that make up her model: the role of instructor, student responsibility for learning, function of content, student assessment, and the balance of power. A process of self-analysis is embedded in each of the many ways she describes these five elements. Four levels of self-examination of one's practice are interwoven with all five of the elements of the model distinguishing whether the instructor would identify their practice as instructor-centered or minimally, mostly, or extensively learning-centered. This section ends with guidance for the instructor to gradually implement learning-centered teaching and deal with barriers to that implementation.

The second section consists of three chapters that cover assessing learning-centered teaching through the use of rubrics. These rubrics offer detailed guidance for assessing oneself, a course, or a program. The author provides direction for choosing actions to assess and analyzing and reporting the data. Charts for self-assessment on each element include directions for describing one's current practice and next steps to further implementation of the model. Blumberg points out ways that these processes of assessment provide opportunities for faculty development, documentation of faculty progress in implementing learning-centered teaching, and possibilities for scholarship of teaching.

This volume is more useful for the religion and theology instructor than many methods texts because it focuses on discrete but clearly defined practices that are broadly applicable. One can benefit greatly from this bountiful book without reading every chart or needing to explore every practice. 